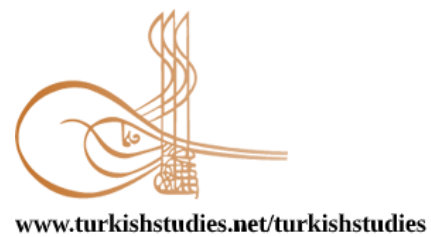

Turkish Studies

www.turkishstudies.net/turkishstudies

eISSN: 1308-2140

BALKAN

UNIVERSTTY

Research Article / Araștırma Makalesi

\title{
Ölümünün Yüzüncü Yıldönümünde İlk Kez Yayımlanan Fotoğraflarla Mimar Alexandre Vallaury'nin Mezarı ve Bu Konudaki Düşünceler
}

\author{
Some Thoughts on Architect Alexandre Vallaury's Grave with New Photos in his Centennial \\ Anniversary of Death
}

Mehmet Çağlayan Özkurt*

\begin{abstract}
Alexandre Vallaury was a Levantine architect and professor of architecture who was born in Istanbul in 1850. After his secondary education Vallaury went to Ecole des National Beaux-Arts in Paris, one of the most important education institution in architecture, and studied there for nine years. After his education in Paris, he returned to İstanbul and started crafting his famous works which would leave his mark on Ottoman architecture. In addition to his architectural efforts, Vallaury played an important role in establishing and structuring Sanayi-i Nefise Mektebi Âlisi [the School of Fine Arts] thanks to his close relationship with Osman Hamdi Bey, and taught architecture at this school for twenty-five years. The nationalist tendencies brought about during the Second Constitutionalist period after 1908 shaped and ended the career of the architect. Vallaury, who, upon this development, resigned -or was forced to resign- from his position at the School of Fine Arts, chose to leave Istanbul, moved to Grasse, France and lived the rest of his life there. In the earliest monographic works relating to the the architect's life and family, the grave of the architect was searched in Feriköy Latin Catholic Graveyard in İstanbul; while finding some members of the family in this graveyard, the grave of Alexandre Vallaury was not found. In a PhD dissertation of 2014, it was stated that the architect's Grave is in Grasse, but the study did not supply any visual material about the grave. This study aims to present the visuals of the grave, and supply new information about the architect's life in his centennial anniversary of death.
\end{abstract}

Structured Abstract: In the Ottoman Empire, especially after the Imperial Edict of Gülhane in 1839, the increasing interaction with the West in every aspect brought about important change and transformation in the field of architecture as well. Imperial Architecture Guild, the traditional architecture department of the Ottoman Empire, became insufficient to respond "modern" expectations starting from the mid-19 th century. This revealed that "local elements" would prove to be insufficient as well to respond to the increasing multiplicity of structures shaped by new political and economic developments. In this context, with the aforementioned period and especially in Istanbul, there has been an influx of foreign architects. Among the first visiting foreign architects, Fossati Brothers and William James Smith were the most prominent ones with their contribution to Istanbul. Another important foreign architect that this study focuses on is Alexandre Vallaury who, especially after 1880 s, left a mark on the Ottoman architecture with his works. * Dr. Öğr. Üyesi, Bolu Abant İzzet Baysal Üniversitesi, Güzel Sanatlar Fakültesi, Temel Sanat Eğitimi Bölümü
Asst. Prof. Dr., Bolu Abant İzzet Baysal University, Faculty of Fine Arts, Department of Basic Art Education
ORCiD 0000-0001-6922-7498
mcozkurt@gmail.com
Cite as/ Atıf: Özkurt, M. Ç. (2021). Ölümünün yüzüncü yıldönümünde ilk kez yayımlanan fotoğraflarla mimar
Alexandre Vallaury'nin mezarı ve bu konudaki düşünceler. Turkish Studies, 16(7), 273-283. https://dx.doi.org/10.7827/TurkishStudies.52809

Received/Geliş: 30 September/Eylül 2021

Accepted/Kabul: 27 December/Aralık 2021

Checked by plagiarism software

Published/Yayın: 31 December/Aralık 2021

CC BY-NC 4.0 
Alexandre Vallaury was a Levantine architect and professor of architecture who was born in Istanbul in 1850. After his secondary education Vallaury went to Ecole des National Beaux-Arts in Paris, one of the most important education institution in architecture, and studied there for nine years. Starting from the beginning of $1880 \mathrm{~s}$, he started crafting his famous works which would leave his mark on Ottoman architecture. In addition to his architectural efforts, Vallaury played an important role in establishing and structuring Sanayi-i Nefise Mektebi Âlisi [the School of Fine Arts] thanks to his close relationship with Osman Hamdi Bey, and taught architecture at this school for twenty-five years. The nationalist tendencies brought about during the Second Constitutionalist period after 1908 shaped and ended the career of the architect. Vallaury, who, upon this development, resigned -or was forced to resign- from his position at the School of Fine Arts, chose to leave Istanbul, moved to Grasse, France. Spending the rest of his life there, the architect passed away on May 2, 1921 and was interred in Sainte-Brigitte Graveyard.

First detailed monographic work on architect and professor of architecture Alexandre Vallaury was conducted in 1991 as a PhD dissertation at Hacettepe University by Prof. Mustafa Servet Akpolat, to whom this publication is dedicated. Another dissertation written by Seda Kula Say in 2014 at Istanbul Technical University, provided new information about the architect. In this context, this study aims to provide new findings on the life of Alexandre Vallaury, a prominent architect who left his mark on the Ottoman architecture, in his centennial anniversary of death while supplying a "scientific farewell" in a publication dedicated to our dear professor Prof. Mustafa Servet Akpolat who pioneered the studies on Alexandre Vallaury. Instead of giving detailed information on the life and works of Vallaury, this study aims to make short remarks about the subject and to provide new data and thoughts on, while supplying the visual material for the architect's grave which Akpolat searched in Feriköy Latin Catholic Cemetery in his first and pioneering monography and which, years later, was located by Seda Kula Say in Sainte-Brigitte Graveyard in Grasse, France. In this aspect, the fundamental material of this study are the photographs taken by author Ekin Can Göksoy in June 2020 and shared with us, and our consideration on these photographs.

Architect's grave is located in the middle part of the west wing of the graveyard. As an austerely designed grave, has a cut-stone cross on its top, without any decorations or epitaph. Pedestal of this cross and the rectangular piece covering the grave - maybe the cover of it - was built by a black granite material. In the middle of this rectangular space, inscriptions of "ALEXANDRE VALLAURY" and just below his death date "2 MAY 1921" could be read. Just below this line, the name and death date of architect's -possibly- second wife are inscribed as "CELINE CHAVIN" and "15 Nov 1924" with smaller type size on the black granite. Seemingly a renovated granite space, it is circulated by cut stone blocks. On these blocks, there are two inscriptions: The first one is "FRANZI FRERES" and "CANNES" on the line below. This makes us think that the grave should be implemented by a company called "Franzi Brothers" in Cannes which is located just south of Grasse. The second inscription reads a name: "A. CRESP" This could possibly be the designer or maybe the architect of the grave.

Levantine architect Alexandre Vallaury who enrichened the city by providing his works to the Ottoman capital, Istanbul, left a mark on the Ottoman architecture especially between 1880 and 1908 . His multi-ethnic family, active in bakery and confectionery, helped not only Alexandre Vallaury but also family itself have an important place in our cultural history. Naturally, Alexandre Vallaury, with his works, is the most prominent member of the family. Therefore, new information on Vallaury and his family attract attention generally in cultural history, but specifically in art and architectural history.

The actual location of Alexandre Vallaury's grave has been an important subject for researchers since Prof. Mustafa Servet Akpolat's dissertation in 1991. In his pioneering work, Akpolat searched the grave in Feriköy Latin Catholic Cemetery where some other members of the family had been buried, to no avail. In another study by Seda Kula Say in 2014, it was stated that the architect's Grave is in Grasse, but the study did not supply any visual material about the grave.

Our study presents the visuals for the grave of Alexandre Vallaury, who was a prominent figure of Ottoman architecture, in order to contribute to the "Vallaury studies" in his centennial anniversary of death. Rather than analyzing the grave in terms of art and architectural history, this study aims to provide new data about the architect's life. The inscription of "Celine Chavin" on the grave, just below Vallaury's name, and with smaller type size should be Marie Mathilde Chavin which was introduced as the second wife of the architect in Seda Kula Say's dissertation. In addition, we think that "Franzi Freres / Cannes" is a grave construction firm from Cannes, and "A. Cresp" is the designer or architect of the grave. However, these 
findings beg to be validated by documents or the family members still alive. We hope to find new information in the future.

Keywords: Art History, Architectural History, Ottoman Architecture, Levantine, Alexandre Vallaury.

Öz: Alexandre Vallaury, 1850 yılında İstanbul'da dünyaya gelmiş levanten kökenli bir mimar ve mimarlık eğitmenidir. Vallaury, orta öğreniminin ardından mimarlık eğitimi almak üzere, bu alanda o dönem dünyanın en seçkin eğitim kurumlarından biri olan, Paris'teki Ecole des National Beaux-Arts'a giderek burada yaklaşık dokuz yıl süren bir mimarlık eğitimi almıştır. Eğitiminin ardından İstanbul'a dönmüş ve 1880'lerin başından itibaren Osmanlı mimarlığına damga vuracak olan eserlerini üretmeye başlamıştır. Vallaury bu mimari üretim faaliyetlerinin dışında, Osman Hamdi Bey'le olan yakın ilişkisi sayesinde Sanayi-i Nefise Mektebi Âlisi'nin kuruluş ve yapılandırılmasında da oldukça etkin bir rol üstlenmiş ve bu okulda yirmi beş yıl aralıksız mimarlık eğitmenliği görevini sürdürmüştür. 1908 'de ilan edilmiş olan II. Meşrutiyet sonrası gelişen milliyetçi akımlar, mimarın da kariyerinin şekillenmesi ve sonlanmasında önemli bir rol oynamıştır. Bu gelişmeyle birlikte Sanayi-i Nefise Mektebi'ndeki görevinden istifa eden -ya da istifaya zorlanan- Vallaury, bu tarihten sonra aşama aşama İstanbul'u terk etmiş; Fransa'nın Grasse Kasabası'na yerleşerek, hayatının son dönemlerini burada geçirmiş ve burada ölmüştür. Mimarın yaşamına ve aile köklerine ilişkin yapılmış olan erken monografik çalışmalarda, mimarın mezarı, araştırmacılar tarafindan İstanbul'daki Feriköy Latin Katolik Mezarlığı'nda aranmış ve ailenin kimi üyelerinin burada olduğu saptanmış fakat Alexandre Vallaury'nin mezarına ulaşılamamıştır. 2014 yılında yapılmış olan bir doktora tezinde, mimarın mezarının Grasse'de olduğu bilgisi verilmiş fakat söz konusu çalışmada mezara ilişkin görsel malzeme sağlanmamıştır. Çalışmamız bu anlamda, mimarın ölümünün yüzüncü yılında, mezarının görsellerini bilim dünyasına sunmakta ve mimarın yaşamına dair yeni bilgiler sağlamaktadır.

Anahtar Kelimeler: Sanat Tarihi, Mimarlık Tarihi, Osmanlı Mimarlığı, Levanten, Alexandre Vallaury

\section{Giriş}

Osmanlı İmparatorluğu'nda, özellikle 1839'da ilan edilen Tanzimat Fermanı sonras1, Batı'yla entegrasyonun her düzeyde artması, mimarlık alanında da önemli değişim ve dönüşümleri beraberinde getirmiştir. Osmanlı geleneksel mimarlık teşkilatı olan Hassa Mimarlık Ocağı'nın 19. yüzyılın ortalarından itibaren, artık "modern" beklentilere cevap veremez hale gelmiş olması, yeni siyasal ve ekonomik koşullarla şekillenen ve artan yap1 çeşitliliğin "ulusal unsurlarla" çözülemeyeceği gerçeğini ortaya koymuştur. Bu bağlamda, söz konusu dönemle birlikte, özellikle başkent İstanbul'a bir yabancı mimar akınının başladığı görülmektedir. İlk gelen yabancı mimarlar arasında Fossati Kardeşler ile William James Smith yapılarıyla en dikkat çeken isimler olmuşlardır. ${ }^{1} \mathrm{Bu}$ çalışmamızın odaklanmış olduğu, dönemin bir diğer önemli yabancı mimarı ise özellikle 1880'lerin başından itibaren yapılarıyla Osmanlı mimarlığına damga vurmuş olan Alexandre Vallaury'dir. Yalnız Vallaury, diğer yabancı mimarlardan farklı olarak, ailesi Osmanlı coğrafyasında yaşamış ve kendisi de İstanbul'da dünyaya gelmiş olan bir levantendir. Aşağıda, yaşamı ve eserleri hakkında kısa bilgiler verilecek olan mimar, İstanbul'da doğup büyümüş, Paris'te mimarlık eğitimi almış ve sonra tekrar İstanbul'a dönerek burada mimarlık faaliyetleri ile eğitmenlik görevini bir arada sürdürmüştür. 1908 yılında gerçekleşen ve Türk siyasal tarihinde önemli dönüşümlere neden olan II. Meşrutiyet, mimarın mesleki kariyeri ile kişisel yaşamının son dönemlerinin şekillenmesinde önemli bir rol oynamıştır. Alexandre Vallaury'nin, kendisinden önceki aile bireylerinin genelinden farklı olarak, 1909 sonrasında aşama aşama İstanbul'u terk edip, ülkesi Fransa'ya dönerek, burada bir "emeklilik hayatı" sürmeyi tercih ettiği ve hayatını orada kaybedip, yine orada defnedildiği görülmektedir.

\footnotetext{
${ }^{1}$ Konu hakkındaki ayrıntılı bir çalışma için bkz. Can, C. (1993). İstanbul'da 19. Yüzyıl Batılı ve Levanten Mimarların Yapıları ve Koruma Sorunları. (Yayımlanmamış doktora tezi). Yıldız Teknik Üniversitesi Fen Bilimleri Enstitüsü.
} 
Mimar ve mimarlık eğitmeni Alexandre Vallaury hakkında, ilk detaylı monografik çalışma, bu yayının da ithaf edilmiş olduğu, Prof. Dr. Mustafa Servet Akpolat tarafından Hacettepe Üniversitesi'nde hazırlanmış bir doktora tezi olarak 1991 yılında ortaya konulmuştur. 2014 yılında Seda Kula Say tarafından İstanbul Teknik Üniversitesi'nde hazırlanmış olan bir diğer doktora teziyle de Alexandre Vallaury hakkında kapsamlı yeni veriler bilim dünyamıza kazandırılmış ve ayrıca bizlerin de (Alexandre Vallaury'nin Sanayi-i Nefise Mektebi'nden istifa dilekçesinin ilk kez yayımlanması gibi) kimi çalışmalarıyla mimar hakkında birçok bilinmez günışığına çıkarılmıştır. ${ }^{2}$

Bu bağlamda çalışmamız, hem Osmanlı mimarlı̆̆ının bir dönemine damga vurmuş önemli bir mimar olan Alexandre Vallaury'nin yüzüncü ölüm yıldönümünde onun yaşamına dair yeni veriler sağlamayı ve hem de Vallaury konusundaki monografik çalışmaların ilk verilerini oluşturarak, bu alanda çalışmalar sürdürmekte olan bizlere yeni kanallar açmış olan sayın hocamız Prof. Dr. Mustafa Servet Akpolat'a ithaf edilen bir yayında, hocamıza "bilimsel bir veda" etmeyi amaçlamaktadır.

Çalışmamız, Vallaury'nin yaşamı ve eserleri hakkında detaylı bilgiler vermek yerine, bu konuda kısa anımsatmalar yapıp; mimarın, Akpolat'ın ilk ve öncü monografik çalışmasında izlerini daha çok Feriköy Latin Katolik Mezarlı̆ğ'nda aradığı ve uzun yıllar sonra Seda Kula Say tarafından, Fransa'nın Grasse Kasabası'ndaki Sainte-Brigitte Mezarlı̆̆g'nda olduğunu tespit ettiği mezarını, ilk kez görsel malzemelerle ortaya koyup, bu konuda yeni veri ve değerlendirmeler sunmaktadir.

$\mathrm{Bu}$ doğrultuda, bu çalışmanın ana malzemesini de Yazar Ekin Can Göksoy tarafından Haziran 2020'de çekilerek tarafımıza iletilmiş olan fotoğraflar ve bu fotoğraflar üzerinden yapmış olduğumuz değerlendirmeler oluşturmaktadır. ${ }^{3}$

\section{Alexandre Vallaury Hakkında}

Osmanlı mimarlığının son dönemine yapılarıyla damga vurmuş bir mimar ve aynı zamanda bir mimarlık hocası olan Alexandre Vallaury (Resim 1), levanten ve tanınmış bir ailenin çocuğu olarak 2 Nisan 1850'de İstanbul'da dünyaya gelmiştir.

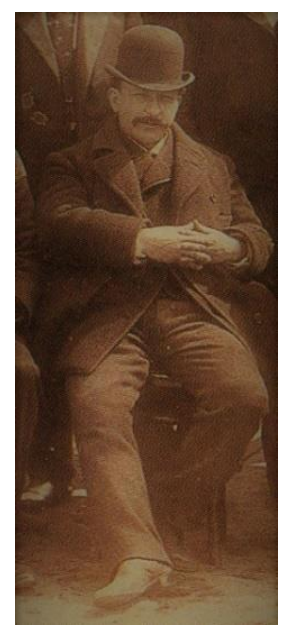

Resim 1: Sanayi Nefise Mekteb-i Âlisi’nin kuruluş aşamasında, mektebin hoca ve öğrencilerini bir arada gösterir fotoğraftan detay: Alexandre Vallaury (Mustafa Servet Akpolat Arşivi).

\footnotetext{
${ }^{2}$ Adı geçen çalışmalara kaynakçada yer verilmiştir.

${ }^{3}$ Kendisi tarafından çekilmiş olan fotoğrafları, tarafıma ileterek, bu çalışmanın ortaya çıkmasındaki en önemli verileri sağlamış olan Yazar Ekin Can Göksoy Beyefendi’ye teşekkürlerimi sunarım.
} 
Mimarın ismi, kimi kayıtlarda ve kimi binalarının cephelerinde İtalyanca Vallauri, kimi kayıtlarda ise Fransızca olarak Vallaury şeklinde görülmektedir. ${ }^{4}$ Söz konusu durum, ailenin uyruğuna dair tartışmaları gündeme getirmiştir. Mimarın, meslek yaşamının ilerleyen dönemlerinde üye olacağ İstanbul'daki 1887-1888 yılı Società Operaia'nın kayıt defterlerinde, 123 numara ile kayıtlı olduğu ve isminin de İtalyanca telaffuza uygun olarak Alessandro Vallauri olarak yazıldığ 1 ve memleket hanesinde ise Torino yazılı olması, ailenin İtalya'nın Torino eyaleti ile bir ilişkisi olduğunu göstermektedir. Fakat bu durum, İtalyan tabiiyetinde olduğuna dair bir kanıt değildir. Ayrıca, 6.7.1896 tarihli bir Osmanlı Devlet Arşivi belgesinde Fransız olduğu ifade edilmektedir. İstanbul Fransız Konsolosluğu tarafindan Vallaury Ailesinin bir mensubuna hitaben yazılmış olan bir açıklama mektubunda, mimarın Fransız tabiiyetine geçiş sürecinin, 10 Nisan 1897 tarihli bir iradeyle başladığı belirtilmekte ve bu tabiiyet değişikliğiyle beraber o zamana değin Alexander Vallauri olarak kullandığ ismini Alexandre Vallaury şeklinde kullanmaya başladığı bilinmektedir. Bu tabiiyet değişikliğinin kabulünde, mimarın Fransız Devleti ve İstanbul'daki Fransız varlığ için yaptığı mimari işlerinin etkin rol oynamış olduğu düşünülebilir (Say, 2014, s. 11-19).

Mimarın çocukluk ve gençlik yıllarına ilişkin detaylı bilgi bulunmazken, orta öğrenimini Saint Joseph Koleji'nde tamamlamış olabileceği düşünülmektedir. Vallaury, 1869 yılında Paris'e giderek mimarlık alanında dönemin en ünlü okulu durumundaki Ecoles des Beaux-Arts'da 9-10 yıl süreli bir eğitim almış ve olasılıkla 1879 yılında eğitimini tamamlayarak İstanbul'a dönmüsstür (Akpolat, 1991, s. 9-10, 120). İstanbul'da, Elifba Sanat Kulübü'nün 1880 yılı sergisindeki proje çalışmalarıyla adını ilk kez duyuran mimar, olasılıkla bu sergi sırasında tanışıı̆̆ Osman Hamdi Bey aracılığıyla, ilk yapısı olan Sanayi-i Nefise Mektebi'ni bu dönemde tasarlayıp gerçekleştirmiştir.

Vallaury'nin bu tarihten başlayarak 1909 yılına kadar devam eden meslek yaşamı, tümü II. Abdülhamid Döneminde geçen ve çoğu İstanbul'da yapılmış çoğunluğu anıtsal nitelikteki yapılarıyla, Sanayi-i Nefise Mektebi Âlisi'ndeki mimarlık hocalığından oluşur (Batur, 1993, s. 151152).

Alexandre Vallaury, 1883-1909 y1lları arasında mesleki anlamda en verimli dönemini geçirmiş ve en önemli yapılarını da bu dönemde gerçekleştirmiştir. Söz konusu yapılar sayılarının çokluğu yanında mimari kalite bakımından da dikkate değer düzeydedir. Mimar, 1890'lara gelinceye değin, Sanayi-i Nefise Mektebi Âlisi (1882), Cercle d'Orient (1884), Hidayet Camii (1887) ve Paris Uluslararası Fuarı için Türk Tütün Pavyonu (1889) gibi yapıları tasarlamıştır. Cercle d'Orient dışında küçük ölçekli olan bu yapılar, Vallaury'nin Osmanlı ve Batı mimarlığını aynı yetkinlikte yorumlayacağının izlerini taşırlar. Mimar, 1892'de Galata'da yaptığı Osmanlı Bankası ve Tütün Rejisi ikiz binasıyla ünlenmeye başlamıştır. Bu dönemdeki diğer büyük boyutlu yapıları arasında Müze-i Hümayun (1891-1907 üç aşamada), Pera Palas Oteli (1893), Yeni Karaköy Han (1893), Union Française (1896), Tokatlıyan Oteli (1897), Prinkipo Palas (1890-1900) ve Düyun-u Umumiye İdaresi binası (1897) sayılabilir. Bu yapıların yanı sıra, Tepebaşı Meşrutiyet Caddesi'nde Decugis Evi (1895) ile yine aynı cadde üzerindeki kendi evi gibi küçük boyutlu yapılar da tasarlamıştır. 1900-1904 yılları arasında Vallaury'nin, daha çok Osmanlı saray çevresi ve üst yönetimi için konutlar tasarladığı görülmektedir. Bunlar arasında Afif Paşa Yalısı (1901), Abdülmecid Efendi Köşkü (1901), Rıdvan Paşa Köşkü ve Vahdettin Köşkü sayılabilir (Akpolat, 1991, s. 14-18).

Alexandre Vallaury, 23 Ağustos 1908 'de II. Meşrutiyet'in ilanı ve Sultan Abdülhamid'in İttihat ve Terakki yönetimi tarafından tahttan indirilmesinin ardından, 2 Mart 1883 tarihinde başladığı Sanayi-i Nefise Mektebi’ndeki mimarlık hocalığı görevinden 13 Ağustos 1908 tarihinde,

\footnotetext{
${ }^{4}$ Mimarın, isminin cephede okunabildiği iki yapıda, Karaköy’deki Ömer Abed Han binasında Vallaury, Beyoğlu Tünel'deki Decugis Evi'nde ise Vallauri ismi okunmaktadır.
} 
sağlık sorunlarını gerekçe göstererek kendi rızasıyla istifa etmiş ya da istifaya zorlanmıştır. ${ }^{5}$ Mimarın, uzun sayılabilecek meslek yaşamındaki dönemin basınına yansıyan son çalışmalarından biri, 1909 yılında düzenlenen Kemaleddin Bey, Vedat Bey, Muzaffer Bey gibi I. Ulusal Mimarlık Dönemi'nin ünlü mimarlarının katıldığı ve sonuçta Muzaffer Bey'in kazandığı Abide-i Hürriyet proje yarışması olmuştur (Akpolat, 1991, s. 20). 1909 Ekim'inde İstanbul'da bilinen son mimari işi ise Eminönü Gümrük binasıdır ve bu binanın açılışında bulunduktan sonra da, bir süre daha resmi belgelerde adına rastlanmaktadır (Say, 2014, s. 20).

Vallaury, uzun ve verimli bir mesleki kariyerin ardından, 1909 civarında aşama aşama İstanbul'u terk ederek eşiyle beraber Fransa'da parfüm endüstrisiyle ünlü Grasse Kasabası'na yerleşmiştir (Resim 2). 2 Mayıs 1921'de burada vefat etmiş olan mimar, Sainte-Brigitte Mezarlı̆̆ına defnedilmiştir (Say, 2014, s. 20).

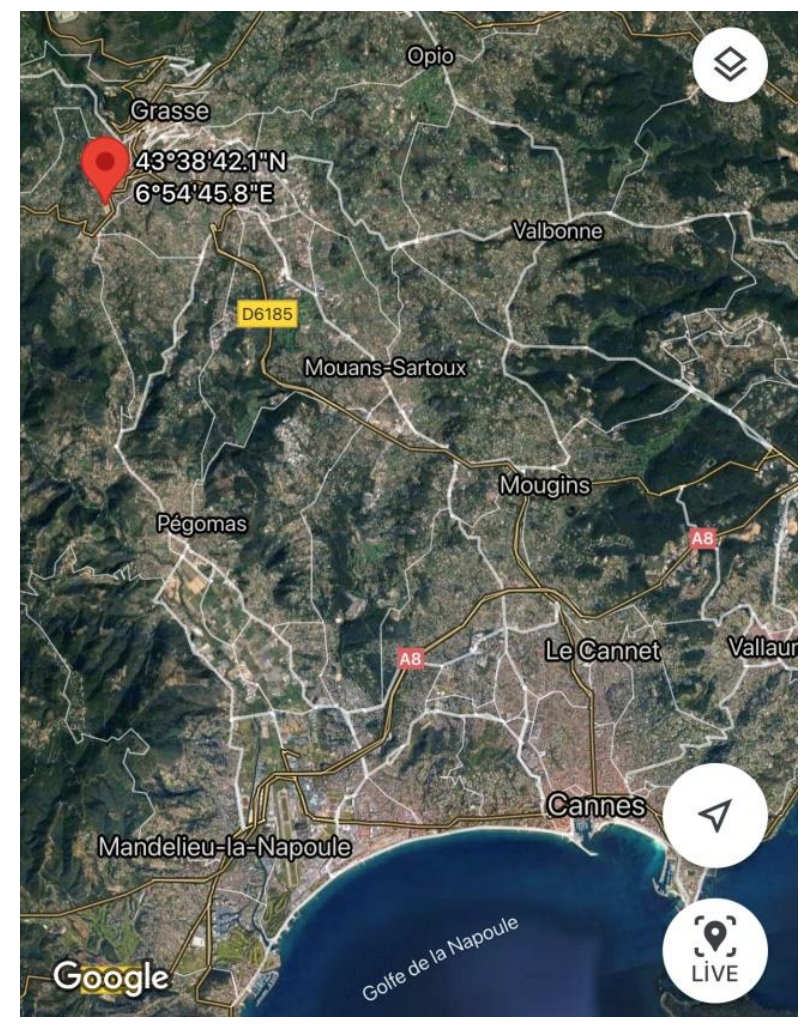

Resim 2: Fransa'nın Cannes Kenti'nin kuzeyinde yer alan Grasse Kasabası'nın uydu haritalarındaki görünümü (Kaynak: Google Maps, erişim tarihi: 24.09.2021).

\section{Alexandre Vallaury'nin Mezarına Dair Gözlemler}

Mimarın, İstanbul'u ne zaman terk edip, Fransa'nın Grasse Kasabasına ne zaman yerleşmiş olduğu net olarak bilinmemekle birlikte, ölüm tarihi 2 Mayıs 1921 olarak mezarının üzerinde okunabilmektedir. Mimarın mezarı, Sainte-Brigitte Mezarlığının yaklaşık batı kenarının ortalarında bir adada yer almaktadır. Mezarlığa ait hava fotoğraflarından, mezarlık alanında oldukça az sayıda ağaç bulunduğu ve Alexandre Vallaury'nin mezarının da bu ağaçlardan hemen birinin altında yer aldığı anlaşılmaktadır (Resim 3).

\footnotetext{
${ }^{5}$ Alexandre Vallaury'nin, Sanayi-i Nefise Mekteb-i Âlisi Müdürü Osman Hamdi Bey’e hitaben kendi el yazısı ile yazıp imzalamış olduğu 13 Ağustos 1908 tarihli istifa mektubunun ilk kez yayımlanıp değerlendirildiği bir çalışma için Bkz. (Özkurt, 2016).
} 


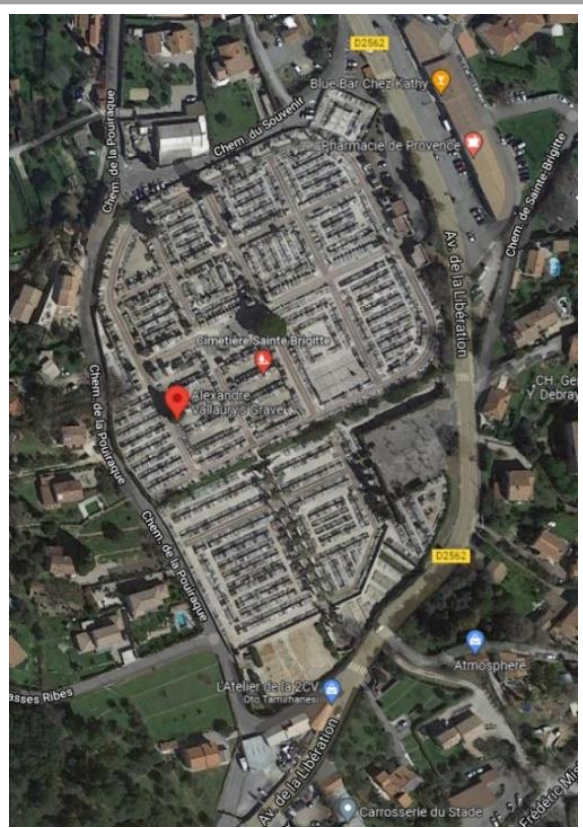

Resim 3: Grasse Kasabası'ndaki Sainte-Brigitte Mezarlığının uydu haritalarındaki genel görünümü ile Alexandre Vallaury'nin mezarının yeri (Kaynak: Google Maps, erişim tarihi: 24.09.2021).

Genel haliyle, yalın bir şekilde tasarlanmış olduğu görülen mezarın başucuna, bezemesiz ve kitabesiz olarak, kesme taş malzemeden bir haç yerleştirilmiştir (Resim 4).

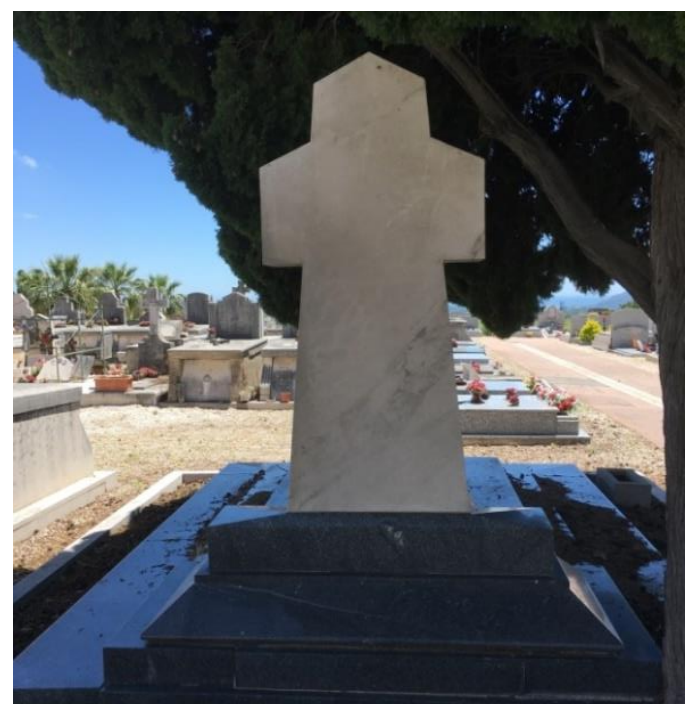

Resim 4: Alexandre Vallaury'nin mezarının dış yüzden görünümü (Fotoğraf: Ekin Can Göksoy, çekim tarihi: Haziran 2020)

Bu haçın kaide bölümü ile mezarı kapatmakta olan dikdörtgen üst bölüm -belki kapaksiyah granit malzemeyle ortaya konulmuştur. $\mathrm{Bu}$ dikdörtgen alanın yaklaşık ortalarında "ALEXANDRE VALLAURY” ve bir alt satırda ise mimarın ölüm tarihi olan 2 Mayıs 1921 tarihi "2 MAY 1921" olarak okunabilmektedir. Bunun altındaki satırda ise -muhtemelen- mimarın ikinci 
karıs1 olan CELINE CHAVIN'in ismi ve ölüm tarihi olan 15 Kasım 1924 tarihi "15 Nov 1924" olarak, mimarın isminden daha küçük puntolarla siyah granit üzerine işlenmiştir. $\mathrm{Bu}$ yüzeyin/kapağın alt bölümüne ise yine yalın bir tasarımla, seramik bir su kabı ya da vazo yerleştirilmiştir (Resim 5).

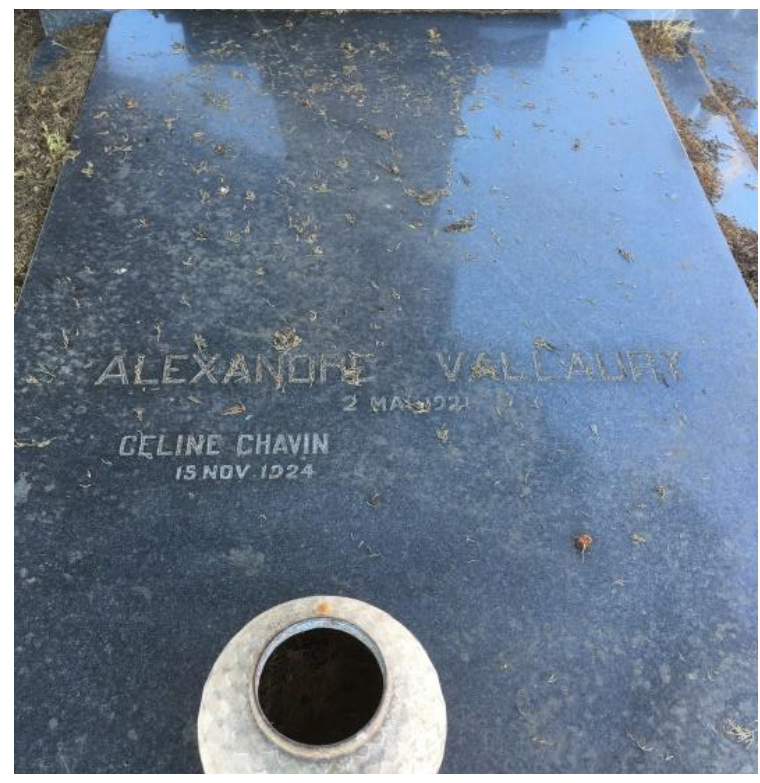

Resim 5: Alexandre Vallaury'nin mezarının üst yüzeyi (Fotoğraf: Ekin Can Göksoy, çekim tarihi: Haziran 2020)

Sonradan elden geçirilerek yenilenmiş olduğu izlenimi veren bu granit alanın çevresinde, mezarın dış sınırlarını belirleyen kesme taş bloklar üzerindeki iki farklı yazı dikkat çekmektedir. Bunlardan ilki: "FRANZI FRERES" ve alt satırında "CANNES" yazısıdır ki bu, mezarın Grasse Kasabası'nın güneyinde önemli bir sahil yerleşimi durumundaki Cannes'da faaliyet gösteren bir mezar yapım firması olan "Franzi Kardeşler" tarafından uygulanmış olduğunu düşündürmektedir (Resim 6). İkinci yazıda ise: “A. CRESP" ismi okunabilmektedir ki, bunun da büyük olasılıkla, mezarın tasarımcısı ya da belki mimarı olduğunu düşünmek mümkündür (Resim 7).

\footnotetext{
6 Alexandre Vallaury ve aile kökleri üzerine araştırmalar yapmış olan Seda Kula Say, Alexandre Vallaury'nin 25.11.1883'te İstanbul St. Maria Drapéris Kilisesinde Maria Constantia Scuro ile evlendiğini, çiftin 1888 yılı civarında Antoine adlı bir çocuklarının dünyaya geldiğini ve 31 Mayıs 1901'de boşanmış olduklarını; kilise kayıtlarından, Constantia'nın 3 Kasım 1917'de İstanbul'da öldüğü ve Feriköy Latin Katolik Mezarlığı'na gömüldüğü bilgisini vermektedir. Say ayrıca, Alexandre Vallaury'nin ikinci evliliğini ise 26 Ekim 1901'de Marie Mathilde Chavin adlı, 1862 İstanbul doğumlu Fransız tebaası bir kadınla yapmış olduğunu ve 13.02.1918 tarihli bir Osmanlı arşiv belgesinden François adında bir oğlu daha olduğu bilgisini vermektedir. (Bkz. Say, 2014, s. 17-18). Say tarafından doğum ve evlilik tarihleri verilmiş olan Marie Mathilde Chavin'in ölüm yeri ve tarihi hakkında bilgi verilmemiştir. Bu bağlamda soyadı aynı olmakla birlikte, kaynaklarda geçen "Marie Mathilde" ile mezarın üzerinde yazmakta olan "Celine" ismi, yine de araştırılmaya muhtaç bir konu olarak durmaktadır.
} 


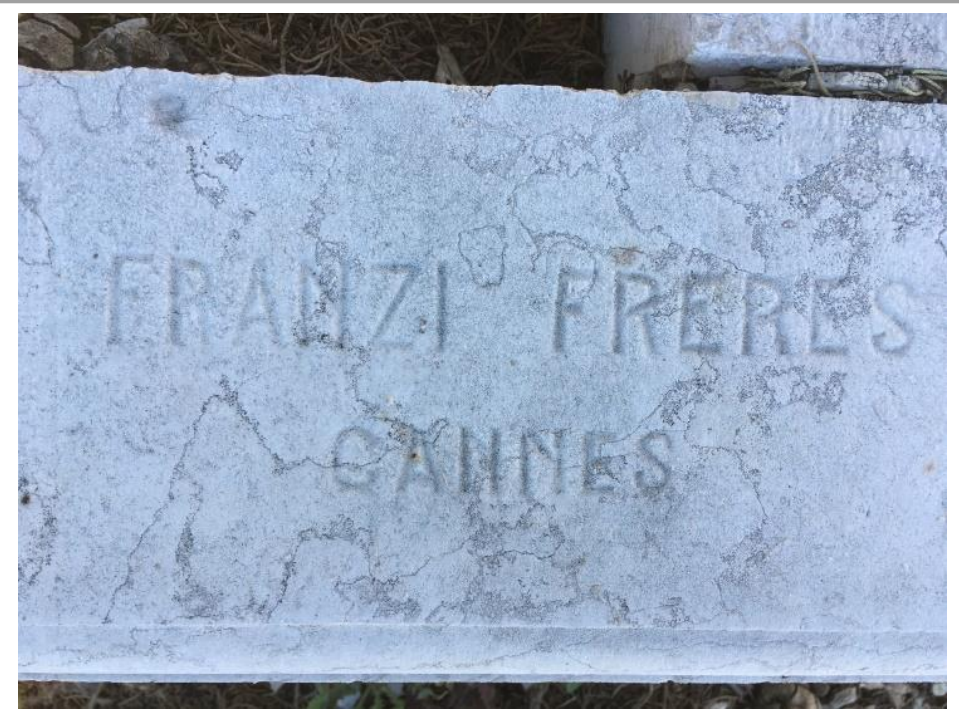

Resim 6: Alexandre Vallaury'nin mezarının dış çevresinde yer alan yazı (Fotoğraf: Ekin Can Göksoy, çekim tarihi: Haziran 2020)

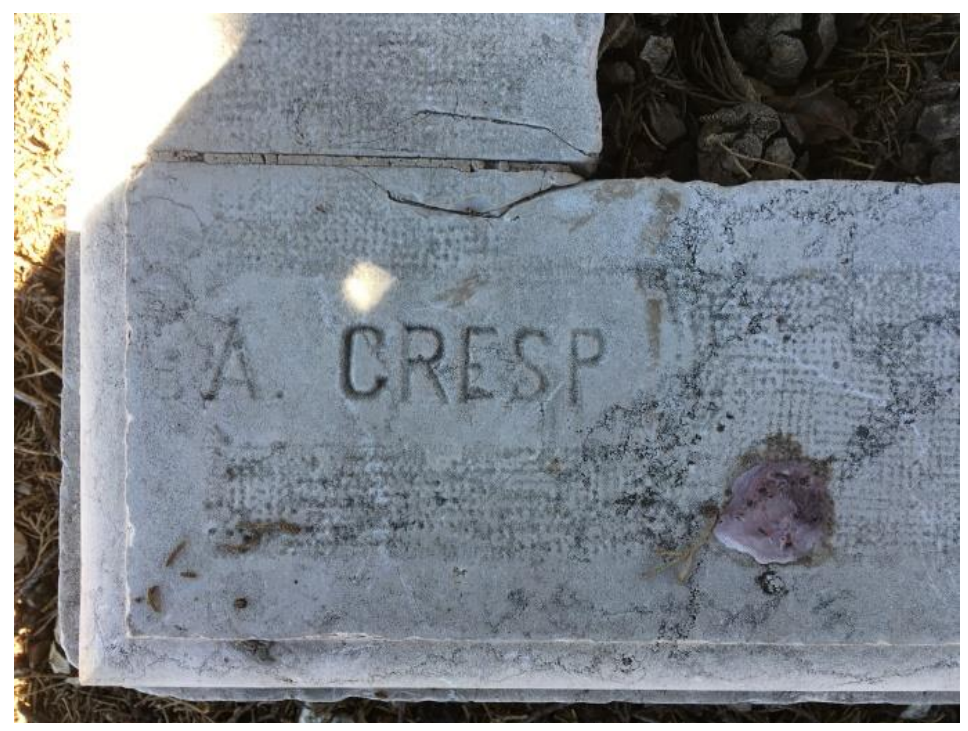

Resim 7: Alexandre Vallaury'nin mezarının dış çevresinde yer alan yazı (Fotoğraf: Ekin Can Göksoy, çekim tarihi: Haziran 2020)

\section{Sonuc}

Eserleriyle, Osmanlı başkenti İstanbul'un imarına büyük katkılar sağlayıp, şehri bu anlamda zenginleştiren levanten mimar Alexandre Vallaury, Osmanlı mimarlığının özellikle 18801908 yılları arasına damga vurmuş, en faal aktörlerinden biri durumundadır. Mimarın yer yer farklı etnik unsurları da içerisinde barındıran, başta pastacılık ve şekerlemecilik alanlarında faaliyet gösteren üyelerden oluşan geniş aile yapısı, aslında sadece Alexandre Vallaury'nin değil, genel itibariyle Vallaury Ailesi'nin kültür tarihimiz içerisinde ayrı bir yer edinmesini sağlamıştır.

Yaptığı işler ve üretimleriyle, doğal olarak Alexandre Vallaury, bu ailenin en önde ve dikkat çeken figürü durumundadır. Bu bağlamda, hem mimarın hem de ailesinin yaşamına dair 
ulaşılan yeni bilgi ve veriler genel itibariyle kültür, daha dar anlamıyla ise sanat ve mimarlık tarihimiz açısından ilgi uyandırmaktadır.

Alexandre Vallaury'nin mezarının nerede olduğu konusu, çalışmalarının bir kısmını Vallaury üzerine yoğunlaştırmış olan biz araştırmacıların, Prof. Dr. Mustafa Servet Akpolat'ın yukarıda da anmış olduğumuz 1991 tarihli çalışmasından bu yana hep ilgisini çeken bir konu olmuştur. Akpolat'ın, Vallaury konusundaki bu ilk ve öncü çalışmasında, mimarın mezarı, ailenin kimi üyelerinin mezarlarının da bulunduğu İstanbul'daki Feriköy Latin Katolik Mezarlığı'nda aranmış ancak bulunamamıştır. Akpolat'ın adı geçen çalışmasından sonra, Vallaury üzerine bu kez 2014 yılında Seda Kula Say tarafından yapılımış olan bir diğer çalışmada ise mimarın mezarının, Fransa'nın Grasse Kasabası'ndaki Sainte-Brigitte Mezarlığı'nda olduğu bilgisi net olarak verilmiş ancak söz konusu bu çalışmada konuyla ilgili görsel veri sağlanmamıştır.

Çalışmamız, son dönem Osmanlı mimarlı̆̆ının en önemli figürlerinden biri olan Alexandre Vallaury'nin mezarını, "Vallaury çalışmaları"na yeni bir katkı sağlamak amacıyla, ölümümün yüzüncü yıldönümü vesilesiyle de görsel olarak tanıtarak, bilim dünyasına sunmaktadır. Burada, mezarın sanat/mimarlık tarihi açısından estetik yönleriyle ele alınıp değerlendirilmesinden daha ziyade, mimarın yaşamına dair yeni veriler sağlamak düşüncesinin daha ön planda olduğunu belirtmek gerekmektedir.

Mezarın üst yüzeyinde, Alexandre Vallaury'nin isminin hemen altında, Vallaury'nin isminden daha küçük puntolarla yazılmış olan "Celine Chavin" isminin, Say'ın, çalışmasında Vallaury'nin ikinci karısı olarak tanitılmakta olan Marie Mathilde Chavin olduğunu düşünmekteyiz. Ayrıca, mezarın çevresinde yer alan "Franzi Freres / Cannes" yazısının Cannes'da faaliyet gösteren bir mezar yapım firmasi; "A. Cresp" yazısının ise mezarın tasarımcısı ya da belki mimarı olduğunu varsaymaktayız. Ancak tüm bu düşünce ve varsayımlar yine de belgelerle ya da en azından ailenin günümüzde yaşamakta olan mensuplarından alınacak sözel bilgilerle doğrulanmaya muhtaç yeni araştırma konuları durumundadır. İlerleyen dönemlerde, bu varsayımlarınızı destekleyecek yeni bilgilere ulaşılmış olmasını ümit ediyoruz.

Bu konudaki son bir değerlendirme hususu olarak Mimar Alexandre Vallaury'nin mezarı ile Vallaury Ailesinin İstanbul'da vefat etmiş olan kimi üyelerinin Feriköy Latin Katolik Mezarlı̆̆ Carré Saint Joseph 9 numarada yer alan "François Vallauri Aile Kabri"ndeki örnekleri karşılaştırıldığında, Alexandre Vallaury'nin Fransa'daki mezarının, diğerlerine oranla oldukça "yalın" ve "iddiasız" bir görünümde olduğunu söylemek mümkündür. Bu durumu belki -en azından İstanbul örnekleri için- Seda Kula Say'ın "Vallauri ailesinin üyelerinin etraflarındaki diğer Levanten ailelere nazaran çok daha sıra dışı ilişkilere ve hayat çizgilerine sahip olduğu gözlemlenmektedir" (Say, 2014, s. 29) değerlendirmesi ile açılamak mümkün olabilir. Bununla birlikte Mimar Vallaury, diğer aile üyelerinden farklı olarak, tüm mesleki kariyerini İstanbul'da geçirmiş olmasına rağmen, emeklilik hayatını Fransa'da sürdürmeyi tercih etmiş ve burada vefat ederek, Grasse Kasabası'ndaki Sainte-Brigitte Mezarlığı'na defnedilmiştir. Mimarın, buradaki mezar taşının yalın ya da iddiasız denilebilecek görünümü, belki bir kasaba mezarlığının "tekdüze ve tektip" görünümüne uyum sağlama arayışı olarak açıklanabilir.

\section{Kaynakça}

Akpolat, M. S. (1991). Fransız kökenli levanten mimar Aléxandre Vallaury [Yayımlanmamış doktora tezi]. Hacettepe Üniversitesi Sosyal Bilimler Enstitüsü.

Batur, A. (1993). 19. Yüzyıl İstanbul mimarlı̆̆ında bir stilistik karşılaştırma denemesi: A. Vallaury/R. D'Aronco. Zeynep Rona (Ed.), Osman Hamdi Bey ve Dönemi Sempozyumu içinde, Tarih Vakfı Yurt Yayınları, 146-158. 
Can, C. (1993). İstanbul'da 19. Yüzyll batıl ve levanten mimarların yapılarl ve koruma sorunları. [Yayımlanmamış doktora tezi]. Yıldız Teknik Üniversitesi Fen Bilimleri Enstitüsü.

Özkurt, M. Ç. (2016). Sanayi-i Nefise Mekteb-i Âlisi'nin ilk mimarlık hocası Alexandre Vallaury'nin istifa dilekçesi, Arkeoloji ve Sanat, 153, 227-240.

Say, S. K. (2014). Beaux Arts kökenli bir mimar olarak Alexandre Vallaury'nin meslek pratiği ve eğitimciliği açısından kariyerinin irdelenmesi [Yayımlanmamış doktora tezi]. İstanbul Teknik Üniversitesi Fen Bilimleri Enstitüsü. 